\title{
ENHANCING ENGINEERING EDUCATION WITH INDIGENOUS Cultures, Pedagogies, Knowledges, And Perspectives: A SERIES OF FACULTY WORKSHOPS
}

\author{
Jillian Seniuk Cicek ${ }^{a}$, Afua Mante ${ }^{a}$, Marcia Friesen ${ }^{a}$, and Randy Herrmann ${ }^{b}$ \\ Centre for Engineering Professional Practice and Engineering Education ${ }^{\mathrm{a}}$; Engineering Access Program (ENGAP) ${ }^{\mathrm{b}}$ \\ Faculty of Engineering, University of Manitoba \\ Jillian.SeniukCicek@umanitoba.ca
}

I acknowledge that I live in Treaty One Territory, on the traditional lands of the Anishinaabeg and the homeland of the Métis Nation. I work in Winnipeg, at the crossroads of the Anishinaabeg, Métis, Nehiyawak (Ne-hi-ya-wak), Dakota and

Oji-Cree Nations.

I respect the Treaties that were made on these territories, I acknowledge the harms and mistakes of the past, and dedicate myself to moving forward in partnership with Indigenous communities in a spirit of reconciliation and collaboration.

\begin{abstract}
In the Faculty of Engineering at the University of Manitoba, we are committed to creating belonging for Indigenous and non-Indigenous students and faculty by fostering shared values and developing $a$ shared approach to engineering education. In the spirit of this commitment, a team of four from the Faculty of Engineering has been funded to design a series of seven engineering specific faculty workshops to help build good relationships between Indigenous and non-Indigenous engineering students, faculty, and staff. Our goal is to enrich engineering education by learning how engineering is relevant to Indigenous Peoples from Indigenous perspectives, with the ultimate objective to integrate Indigenous values, knowledges, perspectives, and design principles into engineering teaching and learning in relevant, genuine, and good ways. This Engineering Education Practice Paper presents the design of the seven workshops, and briefly introduces the conceptual framework that guides the team's approach.
\end{abstract}

Keywords: Indigenous perspectives; engineering education; faculty workshops; shared approach; Sacred Hoop.

\section{INTRODUCTION AND MOTIVATION}

Recently, Kevin Chief, Vice President of the Business Council of Manitoba, was an invited speaker at our Engineering Faculty Council. He spoke about the Treaty Acknowledgment that was made at the outset of his presentation, and emphasized that "once you do the treaty acknowledgment, put that lens on. It doesn't always make sense, but when it does, add that Indigenous perspective" [1].

The fastest growing demographic is Indigenous Peoples - at four times the rate of other populations [2]. Between 2016 - 2026, 350,000 Indigenous youth will be turning 15 [1]. Our history of colonialism and racism in Canada has created troubled relations between Indigenous and non-Indigenous people [3][4]. Part of this dark history is rooted in Canada's Indian Residential Schools (IRS) Act, where an estimated 150,000 First Nations, Inuit and Métis children were removed from their families and exposed to horrific abuses, loneliness, and alienation [5]. We are living in disruptive times with our youth entering the work force in an era characterized by profound economic, social, and technological change [6]. We are faced with grand challenges in the 21st century, many which are a direct result of our human past, and are now part of our young people's legacy.

Treaties are our collective history, and may be considered a grand challenge in Canada. How do we find a path forward? The Truth and Reconciliation Commission of Canada (TRC) was struck in 2008 as part of the IRS Settlement Agreement. The TRC's 94 Calls to Action include reconciliation through education, which, for higher education translates in part as the inclusion of Indigenous perspectives and content into curricula [7][8]. The challenge is to do this in the right way. We must create an approach where First Nations, Métis, Inuit, and Non-Indigenous peoples work in partnership; an approach that validates our treaty acknowledgment, and builds 
belonging for a generation of young people faced with tremendous challenges and different histories.

In the Faculty of Engineering at the University of Manitoba, we are committed to walking forward together, to create belonging for Indigenous and non-Indigenous students, faculty, and staff by fostering shared values and developing a shared approach to engineering education. In the spirit of this commitment, a team of four faculty members has been funded to design a series of seven engineering specific faculty workshops to help build good relationships. Our goal is to enrich engineering education by learning how engineering is relevant to Indigenous Peoples from Indigenous perspectives, with the ultimate objective to integrate Indigenous values, knowledges, perspectives, and design principles into engineering teaching and learning in relevant, genuine, and good ways. This Engineering Education Practice Paper briefly introduces the conceptual framework that guides the team's approach and presents the design of the seven workshops.

\section{INTEGRATING PERSPECTIVES}

In the Beginners Guide to Incorporating Aboriginal Perspectives into Engineering Curricula [9], the authors indicated that for engineering educators to meaningfully integrate Indigenous perspectives into the engineering curricula, three different perspectives - the "dominant perspectives', “engineering perspectives", and "Indigenous perspectives" - must be considered in unison to establish the value and usefulness of integrating Indigenous perspectives into the curricula.

The dominant perspectives are the commonly held views woven through the fabric of society, which often go unnoticed and unquestioned. In North America, the dominant perspectives are established on western European settler's traditions, which view resources as economic commodity for "now" and are "individualistic" centered [9]. In contrast to these "dominant" perspectives, Indigenous perspectives are "pluralistic," and established on their connectedness to land and kin [9]. This places equal value on all lives and equal responsibilities on them as stewards of the earth.

Considering the differences in the "dominant" and Indigenous perspectives, it is important to understand engineers' perspectives. Engineers view themselves as "problem solvers" where they identify gaps in service, performance, comfort, and access to provide the "superior" solution to those gaps in a defined way [9]. However, since engineering training is heavily Eurocentric, there is a high tendency to find solutions to problems through the "dominant" lens without paying much attention to factors other than economic values [10][11]. This type of training has arguably led to many engineering failures that have caused irrevocable damage to Indigenous communities [10][11], such as the impact of hydro dam projects in Manitoba [12].

In our fast-paced world, which is economically driven, tasking an engineer with little to no knowledge of Indigenous ways of life with developmental projects for Indigenous Peoples and communities will be a disservice to the engineer, to the profession, and most of all, to the Indigenous communities the engineer is working with. Students need to be exposed to Indigenous values, knowledges, perspectives, and design principles and recognize their importance, especially in our quest for sustainable ways to ensure food security and resolve climate change issues. From these perspectives, students will understand that developmental projects should not be exclusively economically driven but rather a holistic consideration of the total wellbeing of human beings, communities, and the environment need to be considered for the benefit of all.

To a large extent, the Manitoba engineering industry relies on our institutions to train competent students for the profession. This makes it imperative to actively integrate Indigenous values, knowledges, perspectives, and design principles into engineering curricula to build student capacity to work collaboratively with Indigenous Peoples and communities and adapt Indigenous values and principles in their professional practice. Moreover, we have an ethical obligation to train more Indigenous engineers, as less than one percent of engineers in Canada are Indigenous [13]. This not only is an inaccurate reflection of our population, but a failure to harness the benefits that could result from the plethora of knowledge, skills, and values inherent in the diversity of our province and country. This Indigenous Initiatives Fund project aims to further diversify engineering education and ultimately, attract a more diverse population to engineering.

\section{CONCEPTUAL FRAMEWORK}

The series of engineering specific faculty workshops has been designed using the Anishinaabe (Ojibwe) teaching of the Scared Hoop as offered to us by the Indigenous Initiatives Educator at our university [14]. The Sacred Hoop provides a holistic framework in which to situate the complete workshop series, as well as guide the decisions made in the design and facilitation of each individual workshop. The project team members are working closely with an Indigenous Elder-in-Residence in the faculty, who uses the First Nations traditional teaching of the Medicine Wheel to help people connect to their inner strength and weaknesses, and with an Indigenous Initiatives Educator to ensure that all elements of the Sacred Hoop conceptual framework are developed in a good way [14][15].

In conjunction with this IIF project, a group of engineering educators in the Faculty of Engineering at the 
University of Manitoba that includes two of our IIF team members, have used the Sacred Hoop framework to reconceptualize the Canadian Engineering Accreditation Board (CEAB) graduate attributes, and engineering for sustainability [16]. In this conceptualization, engineering for sustainability has four pillars: the cultural, social, environmental, and economic aspects. In the Sacred Hoop framework the East, where the Spirit aspect resides, is where the CEAB graduate attributes Design, Use of Engineering Tools, and Lifelong Learning ("innovation and creativity") are positioned, with the Cultural element of design for sustainability. The South direction has the Emotion aspect, where we've positioned Professionalism, Impact of Engineering on Society and the Environment, and Ethics and Equity ("ethical reasoning") and the Social pillar of design for sustainability. The West has the Physical aspect, and there the "interpersonal skills," comprised of Communication Skills, Individual and Teamwork, and Economics and Project Management are located, with the Environmental pillar of sustainability. The North holds the Mental aspect, and there we position "problem solving," which comprises Knowledge Base for Engineering, Problem Analysis, and Investigation, as well as the Economic pillar for sustainability (REES). These four directions are described by our Indigenous Initiatives Educator as, What is my story?, How did I get here?, Where am I going?, and What have I learned? [16].

Our Indigenous Initiatives project team has built on this conceptualization of the Sacred Hoop in this workshop series by aligning individual workshops and events with the elements in the Sacred Hoop (see section 4.1 and Appendix 1). Additionally, we conceptualize the whole workshop series as a circular journey. Our Elderin-Residence suggested that we begin the cycle of the workshop series in a good way, by opening it in ceremony and with prayer. With his guidance, we invited the Faculty of Engineering Dean, Associate Deans, Department and Associate Heads, and the Directors of the Co-operative Education and Industrial Internship (Coop/IIP) program, the Internationally-Educated Engineers Qualification (IEEQ) program, Women in Science and Engineering (WISE) Kid-Netic Program, as well as our engineering Design champions to an opening ceremony conducted by the Elder. We met at Migizii Agamik, the Indigenous Student Centre on campus, where one team leader introduced the workshop series and the Elder. The Elder then welcomed the faculty and spoke of how to begin the project in a good way, referencing the Seven Sacred Teachings, the power of women, who bring life, the power of men, who bring fire, and the power of children and youth, who carry a strong spirit. He led a smudging ceremony outside, so that we were connected to the elements - the ground, the earth, the air, the sky, the sun - while he asked Creator to guide our project and us in a good way. Then we all had lunch together. We plan to repeat this event once again to mark the end of the workshop series in March 2020.

\section{APPROACHES AND WORKSHOP DESIGN}

A team of four faculty and one ENGAP student member from the Faculty of Engineering at the University of Manitoba has been funded to design a series of seven workshops in consultation with an Indigenous Elder, an Initiatives Educator, and the teaching and learning centre at our institution. The Centre for Engineering Professional Practice and Engineering Education and Migizii Agamik, the Indigenous Student Centre at the University of Manitoba are supporting us. The team is comprised of the Director of the Engineering Access Program (ENGAP), a Post Doctoral Fellow, the NSERC Chair in Design Engineering, and an Assistant Professor who teaches engineering communication. The workshops are designed for engineering faculty and staff, and engineering Alumni and Industry members have also been invited. The goals of the workshop series are for participants to see how engineering is perceived from Indigenous perspectives, and to learn how to integrate Indigenous pedagogies, knowledges, perspectives and design principles into engineering curricula, with the ultimate goal of these learnings translating for engineering students into their engineering practice.

To achieve our outcomes, enrich faculty development, and increase collaboration, we incorporated a team position for an ENGAP/Indigenous engineering student(s). The ENGAP program in the Faculty of Engineering at the University of Manitoba was founded 33 years ago, and is considered the most successful program of its kind in Canada, graduating its 100th engineer in 2015 [13]. The program provides academic, personal, financial, and social support for students of Indigenous ancestry to obtain the prerequisites necessary to get into engineering [17].

One ENGAP student contacted us to express interest in participating in this project. This student has participated in the designing of part of the workshop series, ultimately guiding us to add a tour of the National Centre of Truth and Reconciliation as the workshop in the series that was conceived as a space for ENGAP/Indigenous students to share their experiences and perspectives with faculty.

\subsection{Indigenous Initiatives Faculty Workshop Series}

The following section presents a brief description of how the Indigenous Initiatives Faculty Workshops have been conceptualized for the Faculty of Engineering at the University of Manitoba. By the time this paper is presented at the CEEA-ACEG 2019 conference, the opening of the workshop series and the introductory workshop will be complete. 
4.1.1. May 1, 2019 - Opening of Indigenous Initiatives Faculty Workshop Series and Introduction of the Engineering Elder-in-Residence - Faculty Retreat. As part of the Indigenous Initiatives project, an Elder-inResidence has been hired on a part-time basis for the Faculty of Engineering. The Elder has agreed to provide cultural and spiritual guidance for our team, and for the faculty and students in the Faculty of Engineering over the next year. The Elder was introduced at the annual Engineering Faculty Retreat, and guided the opening for the Indigenous Initiatives Faculty Workshop series (described in Section 3).

4.1.2. May 2019 - aadizookann/A Sacred Story Positionality Workshop - What is my story? The Sacred Story workshop is described for engineering faculty and staff as follows: Spirit is story and serves as one of the foundations of Indigenous holistic learning. Stories pass on our histories and teachings and serve as an educational method that sustain and validate our experiences through sharing dialogue and building relationships toward our "truths" in reconciliation. This is the first workshop in a series of workshops that have been designed specifically for Engineering faculty, Engineering professionals and Engineering educators to provide an opportunity for the application of an Indigenous circular design framework within the discipline of Engineering. It aims to create a space to coalesce Indigenous and Western education lenses in engineering education. This first workshop is considered a positionality workshop. It is conceived that the workshop series should begin with the participants positioning their ontology, philosophy, and research in relationship to the land and communities, in order to locate themselves, and begin the process of building good relationships in this journey [14][18]. An Indigenous Initiatives Educator will facilitate this workshop in collaboration with another educator in our community.

4.1.3. June 2019 - Tour - National Centre of Truth and Reconciliation - How did I get here? We support the ENGAP student team member in the design of this workshop as a tour of the National Centre of Truth and Reconciliation, which is located on the University of Manitoba campus. Additionally, we will seek to gather the voices and stories of ENGAP/Indigenous students, both presently enrolled in the engineering program as well as former students, to share collective student experiences and perspectives with faculty. We have applied for ethics to conduct this work.

4.1.4. September 2019 - The KAIROS Blanket Exercise - How did I get here? The Indigenous Initiatives Educator in collaboration with another trained educator will offer the KAIROS Blanket Exercise to our faculty. The KAIROS Blanket Exercise is a role-playing activity, where participants are taken through the pre-contact, treaty-making, colonization, and resistance periods of Indigenous rights history [19]. Participants move in a circle upon a number of blankets that have been laid on the floor. The blankets represent Turtle Island (the Indigenous name for North America). As participants move around, the facilitators narrate the journey, reading from scripts in the voices that include European colonizers, while the blankets are slowly removed until the circle that participants walk in is diminished, representing loss of Indigenous Peoples' lives, rights, cultures, and lands due to disease, residential schools, and land appropriation. Participants are given cards and texts from which they read throughout the process. The activity engages the spirit, emotion, physical, and mental aspects, enabling participants to empathize with Indigenous Peoples.

4.1.5. October 2019 - Indigenous Technologies and LEGO Serious Play Workshop - Where am I going? One of our team members will offer faculty a lecture on Indigenous technologies. This will be followed by an interactive workshop using LEGO Serious Play. In the workshop, participants will be guided by trained facilitators to tell their own stories regarding their understandings of Indigenous knowledges and perspectives in engineering, and to create ways to engage Indigenous knowledges and perspectives in engineering education.

4.1.6. November 2019 - Storytelling and Teaching Café - Where am I going? This workshop will comprise of Knowledge Holders and knowledge keepers sharing their perspectives on the impact of engineering on Indigenous communities, as well as sharing Indigenous values, knowledges, and perspectives as they determine. The second half of the workshop will be a teaching café, where Knowledge Holders, knowledge keepers and participants will mingle with one another, sharing conversations on moving forward in engineering education in partnership with Indigenous Peoples while sharing dinner.

4.1.7. January 2020 - Curriculum Workshop I Adapted to Engineering Content - What have I learned? Curriculum Workshop I will demonstrate how engineering curricula and pedagogy can be intersected with both Western and Indigenous perspectives. An Indigenous Initiatives Educator will facilitate this workshop in collaboration with other educators and leaders in our community.

4.1.8. February 2020 - Curriculum Workshop II Adapted to Engineering Content - What have I learned? Curriculum Workshop II will demonstrate how engineering curricula and pedagogy can be intersected with both Western and Indigenous perspectives. It will build on Curriculum Workshop I. An Indigenous 
Initiatives Educator will facilitate this workshop in collaboration with other educators and leaders in our community.

\subsubsection{May 2020 - Closing of Indigenous Initiatives} Faculty Workshop Series and Farewell to the Elder Faculty Retreat. We propose to close the Indigenous Initiatives Faculty Workshop series in a similar way as it begun - with the Elder guiding the closing of the project in ceremony. We will also propose that we say farewell to the Elder at the annual Engineering Faculty Retreat in May 2020, and determine next steps.

\section{CONCLUSIONS AND NEXT STEPS}

A team of four from the Faculty of Engineering at the University of Manitoba has been funded to design a series of seven engineering specific faculty workshops in collaboration with an ENGAP student, and to hire an Elder-in-Residence to provide cultural and spiritual guidance for our team, and for the faculty and students in the Faculty of Engineering over the next year. Our aim in the project is to help build good relationships between Indigenous and non-Indigenous engineering students, faculty, and staff, and to enrich engineering education by learning how engineering is seen from Indigenous perspectives. Our goal is to facilitate faculty and staff in learning meaningful ways to integrate Indigenous values, knowledges, design principles, and perspectives into the engineering curricula. The series of engineering specific faculty workshops has been designed using the Anishinaabe (Ojibwe) teaching of the Scared Hoop as offered to us by an Indigenous Initiatives Educator at our university. The project team members are working closely with the Elder, Migizii Agamik, the Indigenous Student Centre on our campus, an Indigenous Initiatives Educator, and a team from the teaching and learning centre on our campus to ensure that all elements of the conceptual framework and the workshop series are developed in a good way. This engineering education practice paper presented the motivations for the project, the conceptual framework that guided the team's approach, and the design of the seven workshops,

The Indigenous Initiatives Fund workshop series has already been opened by the Elder-in-Residence in ceremony and with prayer, and the first of the seven workshops, specifically the aadizookann/A Sacred Story Positionality workshop, will be offered next week. The intent is for our IIF team members to describe the experiences of these two events to our engineering education colleagues during the CEEA-ACEG 2019 conference, and to engage in a dialogue with the larger Canadian engineering education community about how to move forward in a good way. This Engineering Education Practice paper will be the vehicle by which our team members can give voice to their perceptions of, and experiences in working on this project.
Integrating Indigenous values, knowledges, perspectives, and design principles into engineering curricula offers a way to enrich engineering education, holistically activate students, and enhance student learning and ultimately, engineering practice. This work is intended to demonstrate to Indigenous and nonIndigenous students, faculty, and staff the Faculty of Engineering's commitment to honouring a shared history, holding shared values, and developing a shared approach in working together towards Truth and Reconciliation in Manitoba, and in Canada.

\section{Acknowledgements}

Our team is grateful to the University of Manitoba Indigenous Initiatives Fund and the NSERC Chair in Design Engineering for funding this project. We are thankful to Leah Fontaine, Colleen Webb, Amy De Jaeger, and Mona Maxwell, our colleagues in the Centre for the Advancement of Teaching and Learning at the University of Manitoba for their insight, support and contributions in the conceptualization, design and facilitation of the Indigenous Initiatives Faculty Workshop series and in the realization of this paper. We are thankful for the guidance and support of Elder Norman Meade, Christine Cyr, and Nancy Ross at Migizii Agamik, Indigenous Student Centre.

\section{References}

[1] Kevin Chief, How is Indigenous Knowledge relevant to engineering? How is engineering relevant to Indigenous People?, presentation to the University of Manitoba Faculty of Engineering, 10 October 2018.

[2] Global News, Canada's Indigenous Population Growing 4 Times Faster than Rest of Country, 2017. Available as of March 3, 2019, from https://globalnews.ca/news/3823772/canadas-growingindigenous-population/

[3] Marcia Friesen and Randy Herrmann, "Indigenous Knowledge, Perspectives, And Design Principles In The Engineering Curriculum," in Proc. CEEA-ACEG Canadian Engineering Education Conf., CEEC18, (Vancouver, BC; $3-$ 6 June 2018), 5 pp., 2018.

[4] J. B. Waldram, Manitoba History: Native People and Hydroelectric Development in Northern Manitoba, $1957-$ 1987: The Promise and the Reality. Saskatoon, SK: University of $\quad 1988$. http://www.mhs.mb.ca/docs/mb history/15/hydroelectricdev elopment.shtml

[5] Indigenous and Northern Affairs Canada, Indian Residential Schools, 2019. Available as of March 3, 2019, from https://www.aadncaandc.gc.ca/eng/1100100015576/1100100015577

[6] Royal Bank of Canada, Humans Wanted: How Canadian Youth Can Thrive in the Age of Disruption. Canada: RBC, 
2018, 44 pp. Available as of March 2018, from rbc.com/humanswanted

[7] Truth and Reconciliation Commission of Canada, Truth and Reconciliation Commission of Canada: Calls to Action, 2015. Available as of January 2019, from https://nctr.ca/assets/reports/Calls_to_Action_English2.pdf

[8] Jonathan Beddoes and Marcia Friesen, NSERC Chair in Design Engineering for Sustainable Development and Enhanced Design Integration. Winnipeg, MB: University of Manitoba, 2018.

[9] J. Kennedy, T. Goldfinch, E. Leigh, T. McCarthy, J. K. Prpic, and L. Dawes, A beginner's guide to incorporating Aboriginal perspectives into engineering curricula. Engineering Across Cultures, 2016.

[10] L. Clarkson, V. Morrissette, and G. Regallet, "Our responsibility to the Seventh Generation: Indigenous Peoples and Sustainable Development," International Institute for Sustainable Development, Winnipeg, 1992. Available: https://www.iisd.org/pdf/seventh_gen.pdf [Accessed March 31, 2019].

[11] T. Goldfinch and J. and Kennedy, "Understanding Indigenous consultation and engagement in engineering education," in Australasian Association for Engineering Education Annual Conf., (Australia), 10 pp., 2013.

[12] APTN National News, Power failure: The Impacts of hydro dams in Northern Manitoba. 2015. Available as of May 2, 2019, from https://aptnnews.ca/power-failure-theimpacts-of-hydro-in-northern-manitoba2/
[13] Amber Skrabek, Engineering Access Program (ENGAP) celebrates 30 years and 100 graduates. University of Manitoba, UM Today News, 2015. Available as of May 2, 2019, from http://news.umanitoba.ca/engineering-accessprogram-engap-celebrates-30-years-and-100-graduates/

[14] Leah Fontaine, Personal Communication, 2019.

[15] Amy De Jaeger, Personal Communication, 2019.

[16] J. Seniuk Cicek, A. Mante, C. Geddert, and L. Fontaine, "Engineering Education Re-interpreted Using the Indigenous Sacred Hoop Framework," in Proc. of the $8^{\text {th }}$ Research in Engineering Education Symposium: Translating Research into Practice (REES), (Cape Town, South Africa. July 10-12), 9 pp., 2019. (Forthcoming.)

[17] University of Manitoba, Engineering Access Program (ENGAP). 2019. Available as of May 2, 2019, from http://umanitoba.ca/faculties/engineering/programs/engap/in dex.html

[18] Marie Battiste, "Creating the Indigenous Renaissance", in Decolonizing Education: Nourishing The Learning Spirit. Saskatoon, SK: Purich, 2013, pp. 68-100.

[19] University of Manitoba. Events Calendar. Available as of February 28, 2019, from http://events.umanitoba.ca/EventList.aspx?fromdate $=7 / 6 / 20$ $17 \&$ todate $=7 / 12 / 2017 \&$ display $=$ Week\&type $=$ public \&eventi $\underline{\mathrm{dn}}=13845$ \&view $=$ EventDetails\&information $\mathrm{id}=29829$ 